\title{
AN INFLUENCE OF MICROSTRUCTURE ON THE MECHANICAL PROPERTIES OF THE CORROSION RESISTANT SUPERALLOY CHS88U
}

\author{
E. V. Monastyrskaia ${ }^{1}$, E. V. Petrov ${ }^{1}$, V. E. Beljaev ${ }^{1}$, A. M. Dushkin ${ }^{1}$ \\ ${ }^{1}$ Federal State Unitary Enterprise Moscow Machine-Building Production Association «SALUT»
}

Keywords: Corrosion resistant superalloy, Microstructure, Heat treatment, Hot isostatic pressing (HIP), Tensile properties, Creep rupture life, DTA, Density, Larson-Miller, Turbine blade.

\begin{abstract}
Nickel based corrosion resistant superalloy ChS88U, containing 16 mass \% Cr, is widely used as a material of gas turbine components. At present, the $\mathrm{ChS} 88 \mathrm{U}$ equiaxed blades have more then $80000 \mathrm{~h}$ operating time in industrial gas turbine. An influence of microstructure on the mechanical properties of the ChS88U alloy is investigated, using the samples after cast, heat treatment (HT) and hot isostatic pressing (HIP) + HT. Typical creep-rupture lives of cast + HT and HIP + HT samples at $900^{\circ} \mathrm{C} / 274 \mathrm{MPa}$ are $271 \mathrm{~h}$ and $316 \mathrm{~h}$, respectively. Mechanical properties of $\mathrm{ChS} 88 \mathrm{U}$ are also compared with those of the ChS70 and In738 alloys. The microstructure of the blade with ChS88U post $30000 \mathrm{~h}$ operating time in industrial gas turbine investigated by SEM is given in the paper.
\end{abstract}

\section{Introduction}

ickel based superalloy ChS88U was developed specifically for the marine and industrial gas turbine applications requiring superior hot corrosion resistance and also a low cost. It is widely used as a material of gas turbine components, including blades and vanes, manufactured by conventional investment casting technology. At present, the ChS88U equiaxed blades have more then $80000 \mathrm{~h}$ operating time in industrial gas turbine.

The ChS88U alloy has a good corrosion resistance, first of all, due to 16 mass \% chromium $(\mathrm{Cr})$ concentration. It is accepted that the temperature capability decreases with increasing of $\mathrm{Cr}$ concentration in superalloys [1], therefore the superalloys for aero-engines - single crystals of third generation contain $2 \ldots 4 \%$ (wt.) $\mathrm{Cr}[2,3]$. The target temperature capability for the superalloys is set at $1100^{\circ} \mathrm{C}$ for $1000 \mathrm{~h}$ creep rupture life. Operating conditions of industrial gas turbines are different from those of aero-engines and require the strength and stability for time $100.000 \mathrm{~h}$ at temperature $900 \ldots 950^{\circ} \mathrm{C}$ with hot corrosion resistance. To provide the high corrosion resistance, superalloys for land-based turbines contain more then $10 \% \mathrm{Cr}$ and the ratio $\mathrm{Al} / \mathrm{Ti} \geq 0,7 \ldots 1,0$ [3]. To provide the long operating time the alloys must have very good phase and structure stability.

The objective of the paper is to describe the results of the study of microstructure, phase stability and mechanical behaviors in view of the use of the alloy in gas turbine of the 100.000 hours operating time.
Experimental Procedure

Material

The corrosion resistant superalloy $\mathrm{ChS} 88 \mathrm{U}$ contains 16 mass $\% \mathrm{Cr}$, the compositional ratio of $\mathrm{Al} / \mathrm{Ti}=0,7$. The total concentration of the refractory elements: tungsten (W) and molybdenum (Mo) is 7,2 wt.\%. The alloy contains trace elements: carbon (C), boron (B), zirconium ( $\mathrm{Zr}$ ), yttrium (Y) and $\mathrm{Hf}$ as the grain and phase boundary strengthening elements. A feature of the composition is of a high concentration of boron - 0,09 mass \%, whereas a number of new superalloys have been developed based on the principle of trace element control $[4,5]$. The chemical composition of the superalloy $\mathrm{ChS} 88 \mathrm{U}$ is given in Table I with the superalloy ChS70 containing no boron as reference.

The ChS88U alloy composition is analyzed with the aid of the d-electrons concept, so that any undesirable phases do not appear in the alloy $[6,7]$. It is known that high strength nickel based superalloys have special value $\bar{M}_{d}: 0,975 \ldots 0,995$. The $\bar{M}_{d}=0,98$ of the alloy ChS88U is set on the upper bound of this range by the given composition of the refractory elements in the alloy.

The alloy was melted by Firth Rixson Superalloys Ltd. (Great Britain) and cast to the equiaxed bars of $15 \mathrm{~mm}$ diameter and $70 \mathrm{~mm}$ in length.

DTA

The temperatures of phase equilibrium are obtained by differential thermal analysis (DTA) in conditions of the heating and cooling rate 20 degree/minute, using cylindrical as cast samples of $7 \mathrm{~mm}$ diameter and $7 \mathrm{~mm}$ in length and nickel reference pattern.

Heat Treatment (HT)

HTs for investigation of the influence of microstructure on mechanical characteristics were performed under air atmosphere in a laboratory furnace. The conditions of solution treatment and precipitation heat treatment of $\gamma^{\prime}$-phase are shown in Table II. 


\begin{tabular}{|l|l|l|l|l|l|l|l|l|l|l|l|l|}
\hline \multicolumn{8}{|c|}{ Table I: Chemical composition in $\mathrm{wt} \%$ of ChS88U and ChS70 alloys (balance: Ni) } \\
\hline Alloy & Co & $\mathrm{Cr}$ & $\mathrm{W}$ & $\mathrm{Mo}$ & $\mathrm{Nb}$ & $\mathrm{Al}$ & $\mathrm{Ti}$ & $\mathrm{C}$ & $\mathrm{Hf}$ & $\mathrm{B}$ & $\mathrm{Zr}$ \\
\hline ChS88U & 11,7 & 15,8 & 5,3 & 1,96 & 0,15 & 3,0 & 4,6 & 0,07 & 0,3 & 0,09 & 0,03 \\
\hline ChS70 & 11,0 & 15,9 & 5,5 & 2,0 & 0,2 & 2,8 & 4,5 & 0,09 & - & - & 0,05 \\
\hline
\end{tabular}

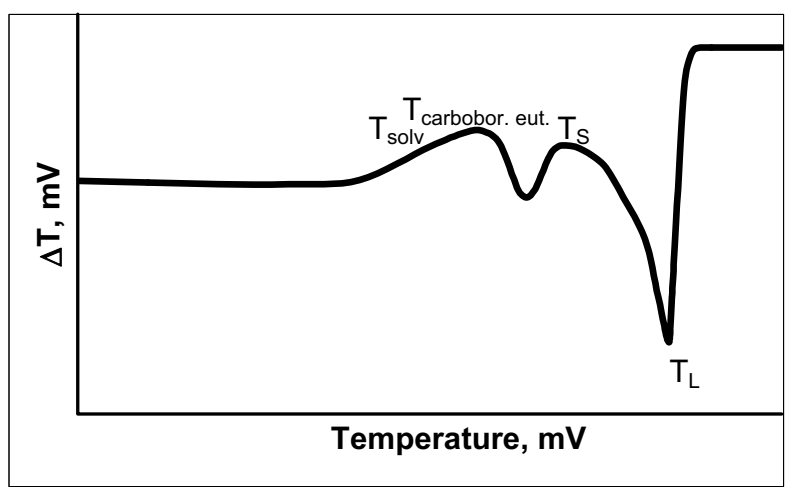

A

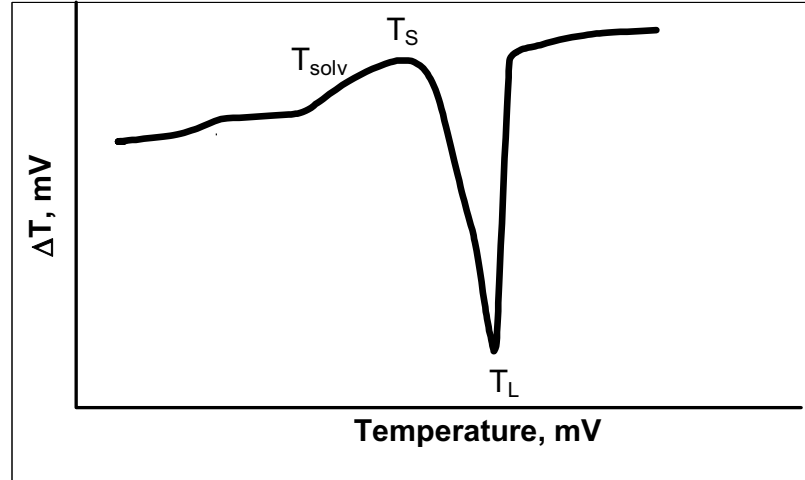

B

Figure 1. Typical DTA curves for ChS88U (A) and ChS70 (B)

\section{$\underline{\text { Heat Treatment }(\mathrm{HT})}$}

HTs for investigation of the influence of microstructure on mechanical characteristics were performed under air atmosphere in a laboratory furnace. The conditions of solution treatment and precipitation heat treatment of $\gamma^{\prime}$-phase are shown in Table II.

Table II: Standard heat treatment of ChS88U and ChS70 alloy

\begin{tabular}{|l|c|c|}
\hline Conditions & $\mathrm{T},{ }^{\circ} \mathrm{C}$ & time, $\mathrm{h}$ \\
\hline solution & 1170 & 4 \\
\hline aging 1 & 1050 & 4 \\
\hline aging 2 & 850 & 16 \\
\hline
\end{tabular}

\section{Microstructure}

The microstructure of the alloys $\mathrm{ChS} 88 \mathrm{U}$ and $\mathrm{ChS70}$ are observed, using scanning electron microscopy (SEM) JSM-5600 equipped with EDX analyzer, after cast, solution treatment, solution and one-step aging treatment, solution and two-step aging treatment, hot isostatic pressing (HIP) and two-step aging treatment in creep ruptured equiaxed specimens and blades after $30000 \mathrm{hrs}$ of operating time in industrial gas turbine.

\section{$\underline{\text { Density }}$}

To acquire data about microporosity, the density of the ChS88U samples is measured by the hydrostatic weighing standard procedure, using high-accuracy weighing machine with the accuracy $0,0001 \mathrm{~g}$.

The densities of the samples after cast, solution treatment and HIP are measured, using the same sample after and before solution and after and before HIP.

\section{$\underline{\text { Mechanical Properties }}$}

As cast, HT and HIP + HT samples are machined mechanically for the creep rupture and the tensile tests. The gauge length of the specimen is $5 \mathrm{~mm}$ in diameter and $35 \mathrm{~mm}$ in length. The creep rupture tests carried out under temperature/stress conditions of $900^{\circ} \mathrm{C} / 274 \mathrm{MPa} ; 800^{\circ} \mathrm{C} / 382 \mathrm{MPa}$. The tensile tests were conducted under temperature conditions of $20 ; 725 ; 800$; $900^{\circ} \mathrm{C}$.

\section{Experimental Results and Analysis}

The DTA curves for the alloys ChS88U and ChS70 show (Figure 1) liquidus, solidus, carbide, carboboride formation and $\gamma^{\prime}$-solution temperature. The most significant difference in the shape of the DTA curve for ChS88U is the endothermic effect at $1190^{\circ} \mathrm{C}$ that is thought to be associated with the melt of carboboride eutectic. The values of the phase transformation temperatures are given in Table III.

Table III: DTA data of $\mathrm{ChS} 88 \mathrm{U}$ and $\mathrm{ChS} 70$ alloys $\left({ }^{\circ} \mathrm{C}\right)$

\begin{tabular}{|c|c|c|c|c|}
\hline Alloy & $\mathrm{T}_{\mathrm{L}}$ & $\mathrm{T}_{\mathrm{S}}$ & $\mathrm{T}_{\text {carbobor eut }}$ & $\mathrm{T}^{\gamma \mathrm{BP}}{ }_{\text {solv }}$ \\
\hline ChS88U & 1363 & 1250 & 1193 & 1162 \\
\hline ChS70 & 1357 & 1251 & - & 1166 \\
\hline
\end{tabular}

Figures 2-5 show the microstructures of the $\mathrm{ChS} 88 \mathrm{U}$. Carbides are observed mostly in the interdendritic regions and also at grain boundaries. The microstructure of the ChS88U alloy includes two types of carbide phases. The main carbide is a script form (MC-I); the bright contrast suggests that the phase contains elements having higher atomic numbers. The second type of carbide (MC-II) is discrete shaped carbide of more dark contrast. The chemical analyses of the phases are given in Table IV. The MC-I phase is (Cr, Mo, W)-enriched. Their morphology «script» (as cast sample) is evidence of the eutectic crystallization (Figure 2). The second type of carbides MC-II are (Ti, W, Hf)-enriched. 
The segregation areas contain small discrete borides and $\mathrm{Hf}$ enrichment.

It is estimated by the alloy design program that the amount of $\gamma^{\prime}$ eutectic or primary is about $3,5 \%$. It is shown by SEM that the size of $\gamma^{\prime}$ eutectic is rather small $1,0 \ldots 5,0 \mu \mathrm{m}$. The chemical analyses of $\gamma / \gamma^{\prime}$ and $\gamma \mathrm{B}^{\prime}{ }_{\text {eu }}$-phases are given in Table IV.

During solution treatment at $1170^{\circ} \mathrm{C}$ the $\gamma^{\prime}$ phase is not totally dissolved (Figure 3). Almost all the $\gamma^{\prime}$ precipitates are dissolved except for the $\gamma^{\prime}$ particles in interdendritic regions and also at the grain boundaries (eutectic areas). The main $\gamma^{\prime}$ phase is due to the solution and re-precipitation of. The average size of the $\gamma^{\prime}$ particles is $\sim 0,1 \mu \mathrm{m}$.

After solution and one-step again treatment the average size of $\gamma^{\prime}$ particles is about $.0,3 \mu \mathrm{m}$ due to the re-precipitation of at $1050{ }^{\circ} \mathrm{C}$. As a result of two-step aging treatment at $1050^{\circ} \mathrm{C}$ for 4 hrs and at $850^{\circ} \mathrm{C}$ for $16 \mathrm{hrs}$ the $\gamma^{\prime}$ size $\sim 0,5 \mu \mathrm{m}$ and cubic shape are optimal for creep resistance (Figure 4).

The main ( $\mathrm{Cr}, \mathrm{Mo}, \mathrm{W})$-enriched carbides have discrete shaped form due partial dissolving at $1170^{\circ} \mathrm{C}$.

For alloys by a large solidification interval, the solidification of the interdendritic eutectic is accompanied by shrinkage. In these closed regions some microporosity appears as a result of bad feeding. One more cause of the microporosity appearance in the ChS88U alloy is a small amount of the incipient melting of carboboride eutectic at the temperature of solution treatment. HIP is an opportunity to get less microporosity and as a result to increase mechanical behaviors especially fatigue properties [10].

The density data of two ChS88U samples: №1 as cast and after solution treatment, №2 as cast and after HIP are given in Table V.

The density of the sample after solution has decreased by $0,03 \%$. The cause of the effect can be the pores aroused after solution of phases, mainly of $\gamma^{\prime}$, over the difference of $\gamma$ and $\gamma^{\prime}$ molar volumes [9]. After HIP the density of the sample has increased by $0,05 \%$ in comparison with the as cast sample. It has to point, that the initial as cast samples chosen for the investigation have the sufficiently density. Therefore, obtained effect of HIP is not very sizeable.

Figure 5 demonstrates the microstructure in the sample after HIP and two-step aging treatment. It differs from the microstructure in sample after standard HT of lesser liquating heterogeneity accompanied by partial MC-I carbides solution and their fragmentation.

The measured mechanical properties of the $\mathrm{ChS} 88 \mathrm{U}$ samples are listed in Tables VI and VII. The samples after HIP + HT have higher stress rupture life and slightly higher tensile properties than the samples after standard heat treatment.

Figure 6 shows the typical tensile stress-temperature curves with the stress maximum in the temperature range 600 to $800^{\circ} \mathrm{C}$ for the standard heat treated $\mathrm{ChS} 88 \mathrm{U}$ samples. The creep rupture data at $700,800,850$ and $900^{\circ} \mathrm{C}$ for $\mathrm{ChS} 88 \mathrm{U}, \mathrm{ChS} 70$, IN738 are plotted in Figure 7. As shown, there is a 40 and $60 \mathrm{MPa}$ loss in creep strength for the ChS70 and In738 accordingly at $900^{\circ} \mathrm{C}, 850^{\circ} \mathrm{C}$ and $800^{\circ} \mathrm{C}$.

The creep-rupture results of ChS88U including long-term data are compared with the ChS70 and In738 data with LarsonMiller Parameter in Figure 8.

SEM microstructures of the blade post $30000 \mathrm{~h}$ operating time in the industrial gas turbine M-70 of the rated capacity $8 \mathrm{Mwt} / \mathrm{h}$ are shown in Figures 9 and 10. Some precipitations of acicular looking TCP phases (Cr \& W rich) are apparent, though not of sufficient volume fraction to de-alloy the material or nucleate creep cracking (Figure 9).

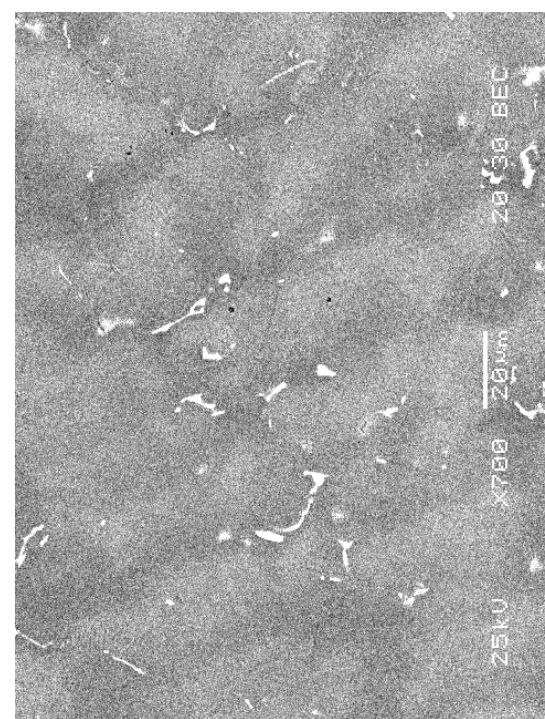

A

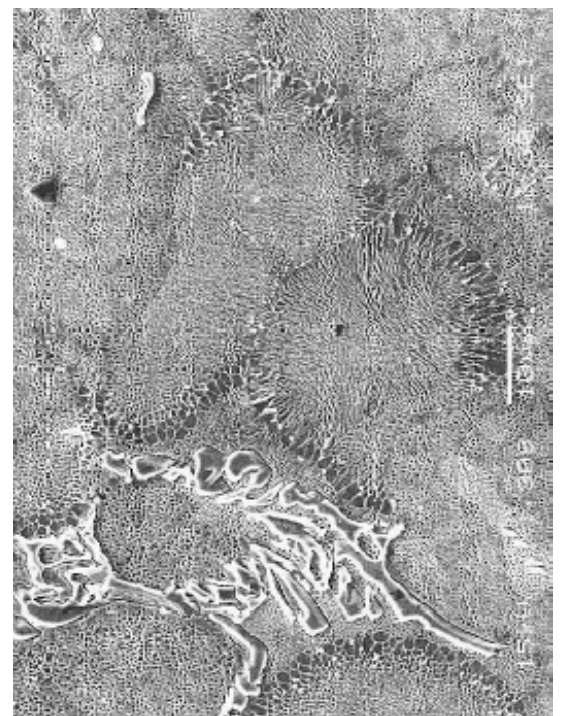

B

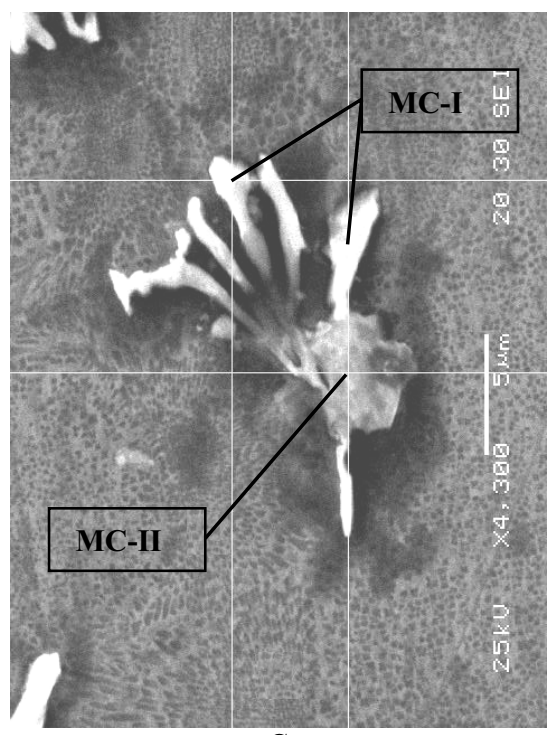

$\mathrm{C}$

Figure 2. As cast ChS88U samples: dendritic structure (A); interdendritic region (B); two types of carbide phases (C) 


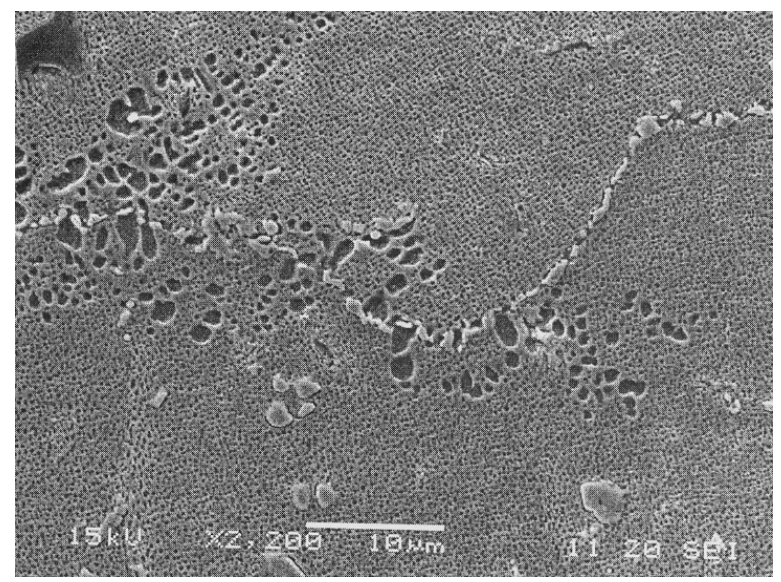

A

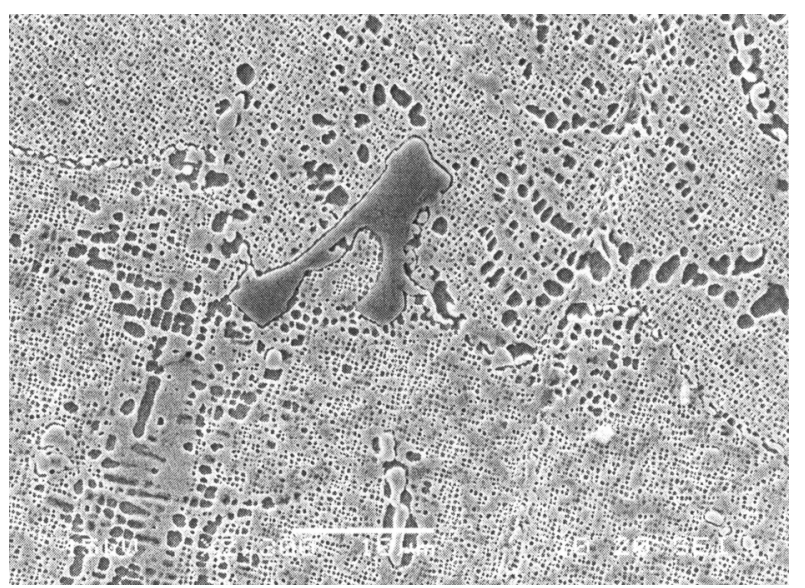

$\mathrm{B}$

Figure 3. Standard heat treated ChS88U sample: grain boundary (A); interdendritic regions (B)

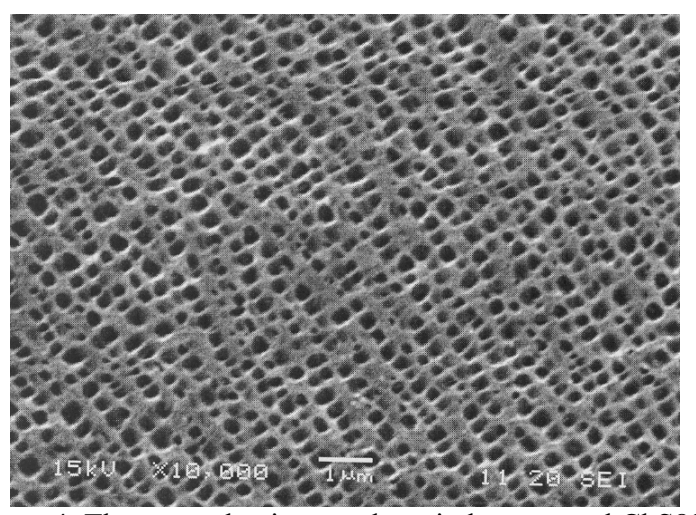

Figure 4. The strengthening $\gamma^{\prime}$ - phase in heat treated ChS88U sample

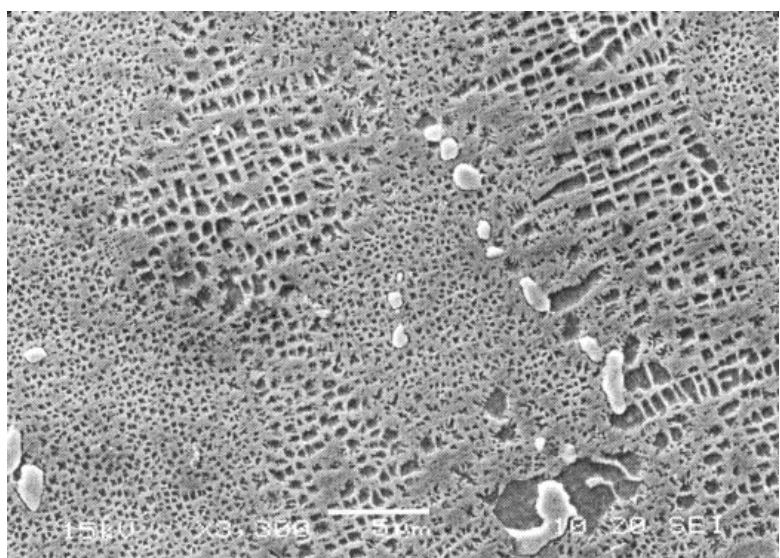

Figure 5. Microstructure in ChS88U sample after HIP + HT

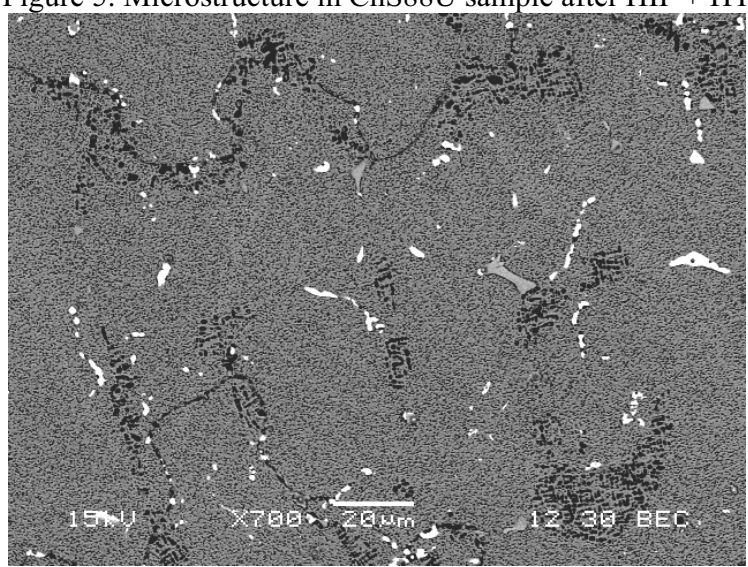

Figure 5. Microstructure in ChS88U sample after HIP + HT 
Table IV: Content of $\mathrm{M}$ in MC, $\gamma / \gamma$ and $\gamma^{\prime}{ }_{\text {eu }}$ phases (ChS88U alloy) (mass fraction in \%)

\begin{tabular}{|c|l|l|l|l|l|l|l|l|}
\hline phase & $\mathrm{W}$ & $\mathrm{Mo}$ & $\mathrm{Cr}$ & $\mathrm{Ti}$ & $\mathrm{Al}$ & $\mathrm{Hf}$ & $\mathrm{Ni}$ & $\mathrm{Co}$ \\
\hline MC-I & 37,62 & 22,06 & 31,47 & 3,31 & - & - & 6,4 & 3,04 \\
\hline MC-II & 32,11 & 5,11 & 1,85 & 39,91 & - & 2,35 & 3,27 & - \\
\hline$\gamma / \gamma^{\prime}$ & 4,18 & 1,84 & 15,54 & 4,27 & 2,23 & - & 63,03 & 11,25 \\
\hline$\left.\gamma / \gamma^{\prime}{ }^{*}\right)$ & 6,3 & 1,5 & 16,1 & 3,0 & 2,1 & - & 59,4 & 11,3 \\
\hline$\left.\gamma / \gamma^{\prime * *}\right)$ & 3,8 & 1,4 & 14,8 & 6,0 & 2,7 & - & 60,0 & 11,0 \\
\hline$\gamma^{\prime}{ }_{\text {eu }}^{*}$ & 0,5 & 1,6 & 5,8 & 11,2 & 7,4 & - & 68,2 & 6,8 \\
\hline
\end{tabular}

*) dendrite area; $* *$ ) interdendritic area

Table V: Density of ChS88U samples as cast, after standard HT and after HIP + HT

\begin{tabular}{|c|c|c|c|}
\hline \multicolumn{2}{|c|}{ Sample } & $\begin{array}{c}\text { Density, } \\
\mathrm{g} / \mathrm{cm}^{3}\end{array}$ & \multirow{2}{*}{$\begin{array}{c}\Delta, \\
\%\end{array}$} \\
\hline \multirow{2}{*}{ №1 } & as cast & 8,2213 & \multirow{2}{*}{$-0,03$} \\
\cline { 2 - 3 } & solution & 8,2192 & \\
\hline \multirow{2}{*}{ №2 } & as cast & 8,2272 & \multirow{2}{*}{$+0,05$} \\
\cline { 2 - 3 } & HIP & 8,2309 & \\
\hline
\end{tabular}

Table VI: Tensile properties of ChS88U samples (mean values)

\begin{tabular}{|c|c|c|c|c|c|}
\hline Sample & $\begin{array}{c}\text { Temperature } \\
\left({ }^{\mathbf{0}} \mathbf{C}\right)\end{array}$ & $\begin{array}{c}0,2 \% \mathrm{YS} \\
(\mathrm{MPa})\end{array}$ & $\begin{array}{c}\text { UTS } \\
(\mathrm{MPa})\end{array}$ & $\begin{array}{c}\text { EL } \\
(\%)\end{array}$ & $\begin{array}{c}\text { RA, } \\
(\%)\end{array}$ \\
\hline as cast & 20 & 919 & 1193 & 10,5 & 12,5 \\
\hline standard HT & 20 & 897 & 1113 & 5,7 & 9,7 \\
\hline standard HT & 600 & 897 & 1113 & 6,0 & 10,0 \\
\hline standard HT & 725 & 837 & 1147 & 10,3 & 10,45 \\
\hline standard HT & 800 & 912 & 985 & 13,4 & 26,18 \\
\hline standard HT & 900 & 657 & 717 & 24,3 & 37,7 \\
\hline HIP + HT & 20 & 924 & 1129 & 7,3 & 14,7 \\
\hline
\end{tabular}


Table VII: Stress rupture life of ChS88U samples

\begin{tabular}{|c|c|c|c|c|}
\hline \multirow{2}{*}{ Alloy } & Sample & $\begin{array}{c}\text { Temperature } \\
\left({ }^{\mathbf{0}} \mathbf{C}\right)\end{array}$ & $\begin{array}{c}\text { Stress } \\
(\mathrm{MPa})\end{array}$ & $\begin{array}{c}\text { Life, } \\
(\mathrm{hrs})\end{array}$ \\
\hline \multirow{2}{*}{ ChS88U } & as-cast & 900 & 274 & 152 \\
\cline { 2 - 5 } & standard HT & 900 & 274 & 271 \\
\cline { 2 - 5 } & standard HT & 800 & 382 & 1000 \\
\cline { 2 - 5 } & HIP + HT & 900 & 274 & 316 \\
\hline ChS70 & standard HT & 900 & 245 & 200 \\
\hline
\end{tabular}

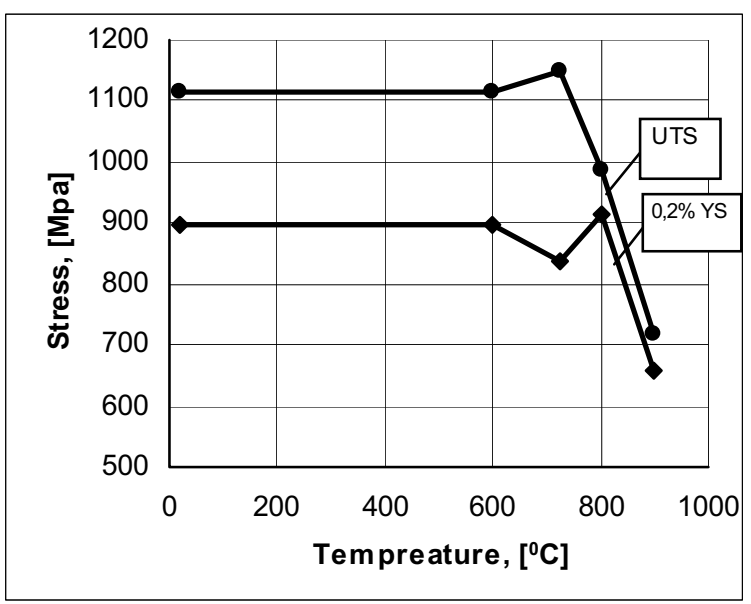

Figure 6. Tensile properties-temperature curves of $\mathrm{ChS} 88 \mathrm{U}$

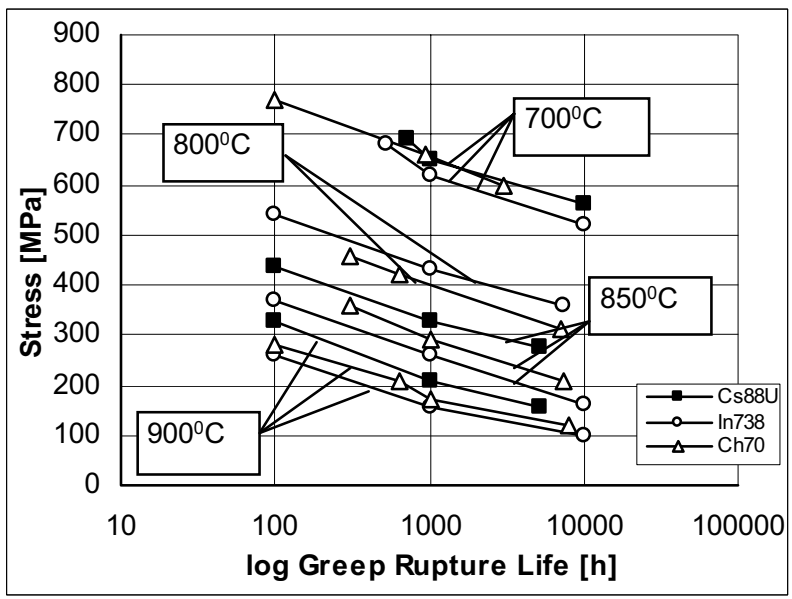

Figure 7. Creep rupture lives of different superalloys 


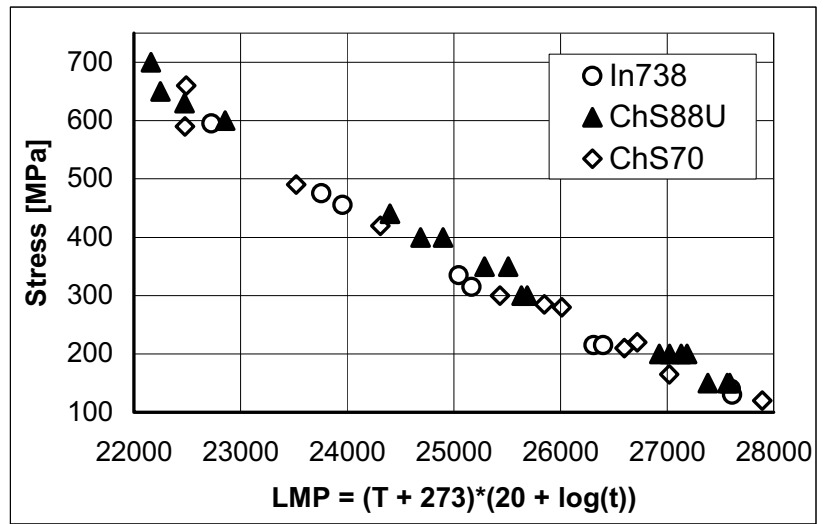

Figure 8. Larson-Miller Plot for comparison between ChS88U, ChS70 and In738 alloys
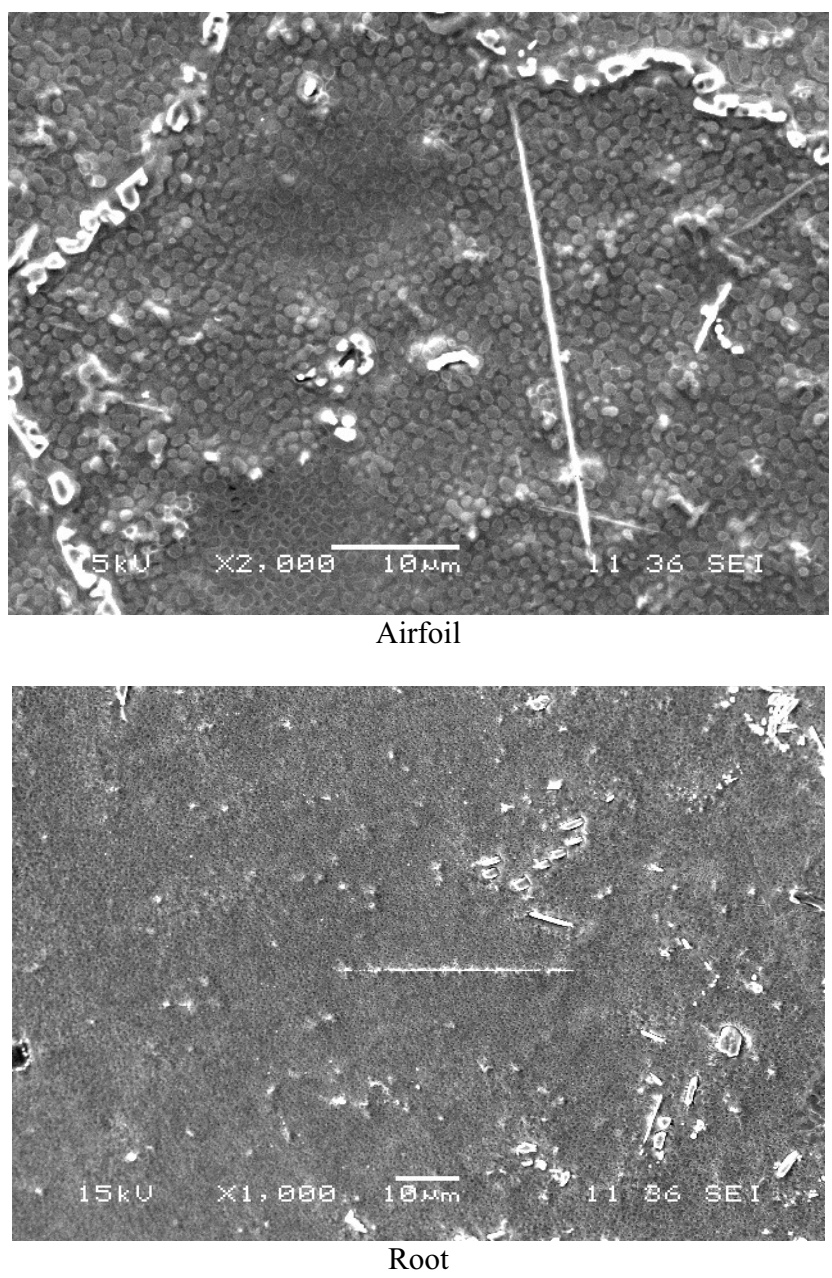

Figure 9. Microstructure in airfoil and root of blade having $30000 \mathrm{~h}$ operating time in industrial gas turbine 


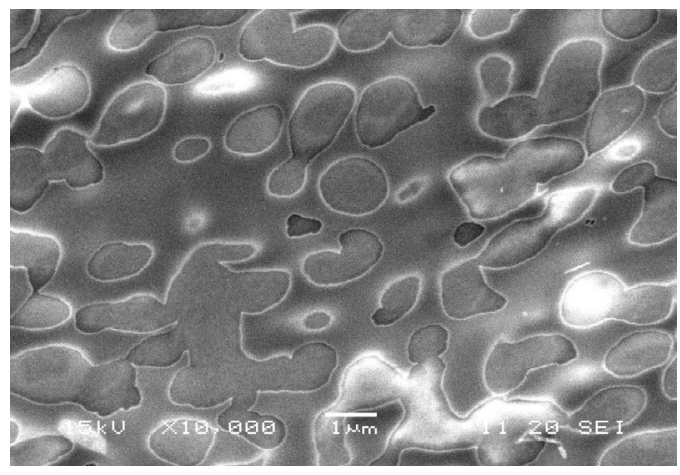

Inlet edge of airfoil

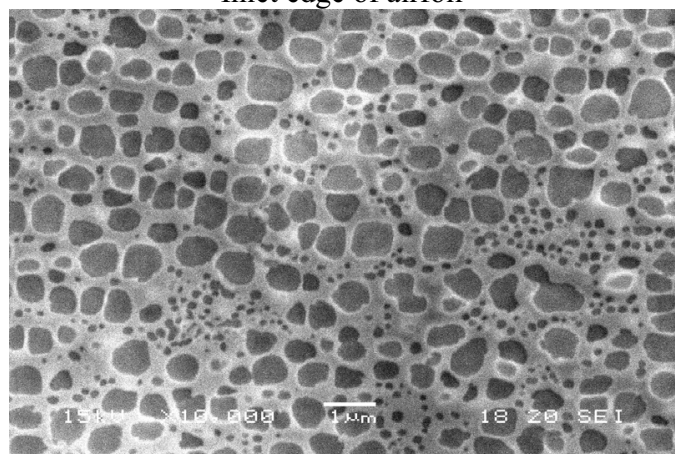

Center of airfoil section

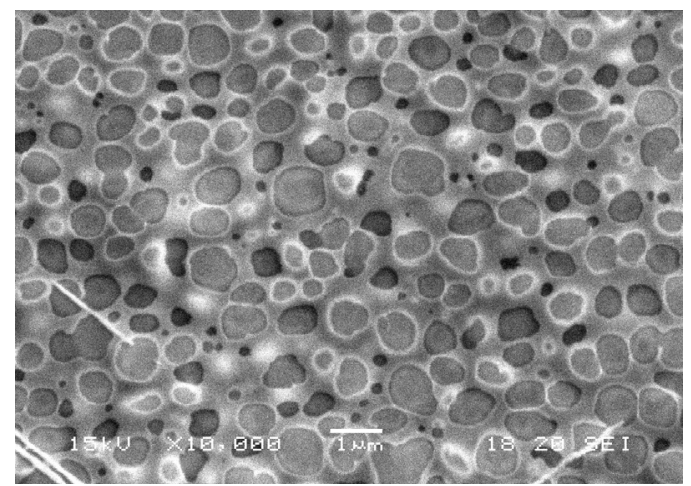

Near outside of airfoil

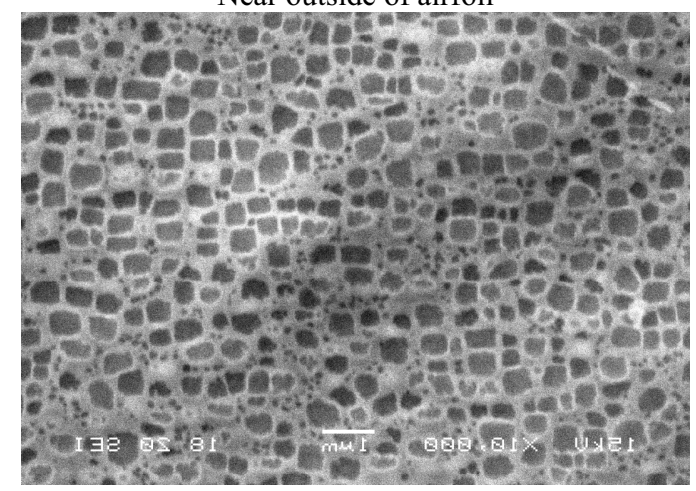

Near of interior cooled surface

Figure 10. Strengthening $\gamma^{\prime}$-phase in the airfoil of blade having $30000 \mathrm{~h}$ operating time in industrial gas turbine

\section{Conclusions}

An influence of microstructure including density of the samples on the mechanical properties of the corrosion resistant $\mathrm{ChS} 88 \mathrm{U}$ alloy is investigated. The following results have been obtained:

1. The ChS88U alloy has an advantage over the ChS70 alloy due to boron and hafnium alloying and over IN738.

2 . The higher stress rupture life and slightly higher tensile properties are obtained after HIP, due to the increase of density of the alloy.

3. The microstructure investigation of the blade post $30000 \mathrm{~h}$ operating time in industrial gas turbine shows a good phase and structure stability of the alloy.

\section{References}

1. R.F. Singer, «Advanced Materials and Processes for LandBased Gas Turbines», Materials for Advanced Power Engineering 1994, Eds. D. Coutsouradis at al, Kulter Academic Publishers, Dordrecht, 1994, pp. 1707-1730.

2. W. S. Walston et.al., «Rene N6: Third generation Single Crystal Superalloy», Superalloys 1996, Eds. R. D. Kissinger et al., TMS, Warrendale, 1996, pp.27-34.

3. N. Petrushin, I. Svetlow, «Physicochemical and structural characteristics of the supeeralloys based nickel», Metals, 2001, № 2, pp. 63-73 (Russia).
4. E. Kablow, I. Svetlow, N. Petrushin, «Superalloys for the casting of blades with directional and single crystal structure», Materials Sciences Transactions, 1997, v.5, pp. 32-39 (Russia).

5. Y. Zhu et. al., «The Development and Long-Time Structural Stability of a Low Segregation Hf Free Superalloy - DZ125L», Superalloys 2000 , Eds. T. M. Pollock et al., TMS, (2000), pp.329-339.

6. M. Morinaga et. al., «New PHACOMP and its Application to Alloy Design», Superalloys 1984, Eds. M. Gell et al., The Metall. Soc. of AIME, (1984), pp.523-532.

7. Y. Murata et. al., «Trace of the Evolution of Ni-Based Superalloys by the d-Electrons Concept», Materials for Advanced Power Engineering 1998, Eds. J. Lecomte-Beckers et al., Forschungszentrum, 1998, pp.1381-1390.

8. V. N. Toloraija, I. L. Swetlow, «An Influence of the Directional Solidification Conditions and Heat Treatment on the Porosity in Nickel Based Single Crystal Superalloys», Metals, 1991, № 5, pp. 70-75 (Russia).

9. S. Hajurow, «Hot Isostatic Pressing of castings», Technology of Light Alloys, 1985, № 10, pp. 43-54 (Russia). 6. 